\title{
The Political Space between Words and Things: Health Claims as Referential Displacement
}

\section{Kim Hendrickx}

To cite this article: Kim Hendrickx (2019) The Political Space between Words and Things: Health Claims as Referential Displacement, Science as Culture, 28:4, 427-448, DOI: 10.1080/09505431.2018.1557629

To link to this article: https://doi.org/10.1080/09505431.2018.1557629

\section{Published online: 20 Dec 2018.}

Submit your article to this journal

Llll Article views: 124

Q View related articles ๘

View Crossmark data $₫$ 


\title{
The Political Space between Words and Things: Health Claims as Referential Displacement
}

\author{
Kim Hendrickx \\ Research Foundation, Flanders (FWO) \& Life Sciences and Society Lab, Center for Sociological \\ Research, Leuven, Belgium
}

\begin{abstract}
In the EU today, health claims on food labels are regulated as a form of information. Before the 2000s, statements referring to health on packaged food were subject to different national regulations across the $\mathrm{EU}$, with different perspectives on where the boundary lies between food and drugs. The turn to more horizontal legislation in EU food law and increased emphasis on the role of information for the functioning of the Single Market does not in itself explain why, and especially how, health-related statements on food products have been turned into information and what consequences this has produced. Construction of such a European 'technological zone', where health claims circulate as a form of information, can be understood as 'information's constitutive outside' (Barry, A. (2006) Technological zones, European Journal of Social Theory, 9(2), pp. 239-253; Barry, A. (2013) Material Politics: Disputes along the Pipeline (Oxford: Wiley-Blackwell)). This outside hinges on technopolitical discussion, lobbying and decisions where the boundary between health and disease is at stake, along with food's materiality. The concept of referential displacement shows how decisions in the regulatory process have transformed controversial references to human health on food labels into 'health claims' as an informational category by shifting the relation between the health claim and its material referents: food itself, health and the body. Referential displacement produces a new kind of information that implies similar efficacy to pharmaceutical drugs, without interfering with the zone or market of pharmaceuticals.
\end{abstract}

\section{Introduction}

We see claims as information, not as food. - Chairman of the European Commission's Standing Committee on the Food Chain and Animal Health ${ }^{1}$

In 2012 the consumer organization Foodwatch named the year's most misleading product: Unilever's cholesterol-lowering margarine Becel ProActiv (called 
Flora ProActiv in the UK). For Foodwatch the margarine was misleading because it is not a food. Instead, Foodwatch argued that a food that has demonstrable effects on the human body, including side-effects, belongs in a pharmacy rather than the supermarket. ${ }^{2}$

The global food market has witnessed a surge in positive references to health benefits on food labels. Since the 1980s and 1990s, we find phrases like 'actively reduces cholesterol' or 'maintains normal bowel function' on the labels of products like margarine, yoghurts, Calcium enriched products, among others. Such phrases suggest that the food product does more than simple nourishment. Current scientific evaluation by the European Food Safety Authority requires a definition and evidence of the effects that go beyond nourishment. But, when does such an effect qualify as medicinal?

When asked whether the boundary between food and drugs is a regulatory issue, official spokespeople for the European Commission (EC) have a straightforward answer: 'We see claims as information, not as food'. The answer was so obvious that such interview situations become embarrassing for the researcher. From a regulatory point of view, food is not the issue, and comparing health claims to drugs and medicinal statements is irrelevant. Health claims are a voluntary form of information on the food label that has to comply to the rules laid down in the Nutrition and Health Claims Regulation (NHCR) where food and its material properties or effects are not part of what defines a health claim. The question then becomes: How are health claims framed as information? What does information mean in this particular case, and what does the concept of information $d o$ ?

In this paper, I analyze the making and implementation of the NHCR, and how the production of information requires specific decisions that affect the referents of that very information. I identify the decisions before, during, and after the making of the NHCR as key moments where one can trace the contours of what Andrew Barry refers to as 'information's constitutive outside' (Barry, 2013). For Barry, the nature of public information is bound up with what cannot be made public (p. 12). More precisely, my analysis traces how health claims became an object of government (Lezaun, 2006) through a regulatory process that turns direct reference to food, health and the body into a constitutive outside in order to produce a new kind of information on the food label, rather than 'additional' statement about the food's beneficial properties. The boundary between food and drugs is an important element of this constitutive outside, as is the relation between information and materiality.

The interview cited above indicates the extent to which food's materiality has been turned into an outside: health claims are information, not food. Turning food into information is not self-evident, and the question of what a health claim may or may not denote (e.g. food composition, health and disease, the human body) resurfaces several times. Each time, the issue is settled by redefining those references. This paper shows how this production of information is 
made possible by what I term referential displacement, reflecting a political process that shifts the relation between information and its referents and, thereby, changing the type of information that is being produced.

Following the theoretical discussion, the paper is structured chronologically around three key moments where juridical and political decisions are made that constitute the health claim as an object of government and a form of information. The first is a 2002 court case before the European Court of Justice (ECJ) that set the regulation of 'health-related statements' as a political priority in the EU. The second is the regulatory response, starting with a legislative proposal in 2003 that initiated the procedure to draft an EU Regulation. The third key moment is the implementation of that Regulation from 2007 onwards, where the European Food Safety Authority (EFSA) starts the scientific evaluation of health claims.

\section{Analytical Perspectives: Information and Materiality}

Functional foods (as products that bear a health claim) and health claims in a broad sense (including nutrition claims) have received attention from a variety of disciplinary angles, including consumer perception and use (Jauho and Niva, 2013; Weiner and Will, 2015); the imagination or configuration of the consumer (Weiner, 2010; Frohlich, 2011); the process of product development (Lehenkari, 2003; Penders and Nelis, 2011); the politics of labeling (Schleifer, 2013; Frohlich, 2017); advertising (Davis and Schneider, 2008); the question whether claims are misleading or not (Williams, 2005; Mariotti et al., 2010; Jauho and Niva, 2013); and critical approaches to industry and reductionism in nutrition science (Nestlé, 2007; Scrinis, 2008, 2013).

In this paper, I move upstream and ask how health claims became objects of government in the first place (Lezaun, 2006), and how they were placed within the juridical framework and provisions concerning labeling and information, rather than, for example, public health. This regulatory process took place at the EU level, where consumer perceptions and legal provisions concerning the distinctions between food and medicine vary across the Member States. The fact that an 'informational turn' has occurred in the EU and US food law, putting the regulatory focus on food labeling information rather than the material composition of products, helps us understand the emergence of a different type of regulation; it is easier and politically less contentious to regulate information than actual food. This, however, does not explain how healthrelated statements on food products have been turned into information and what consequences this has produced.

Studying nutrition labels as information infrastructures in the US context, Frohlich (2017) shows that it is important to attend to how information is produced, and what material consequences this information in turn generates with respect to food production, distribution and consumption. He notes that the 
informational turn has shifted attention to the politics of information, rather than on the food itself. The question of what information does is all the more important, because references to health on food have been, and still are, controversial. EU Member States like Austria, as I discuss below, did not consider them as mere information but as therapeutic claims needing a special assessment and premarket approval.

In this paper, I therefore investigate empirically what information comes to signify in the EU context, and how it depends on what Barry (2013) calls information's constitutive outside'. This concept comes from Barry's analysis of a series of knowledge controversies concerning the construction of the BakuTbilisi-Ceyhan oil pipeline. Barry documents how this construction became a political experiment in transparency about the pipeline in terms of information. Information, however, is never readily available to take, but it must be produced. Information, as Barry shows, becomes a stake in a political climate with transparency among its core values. Rather than simply bringing everything to light, practices and controversies related to transparency revolve around which information is valuable and which information is not.

In analyzing knowledge controversies, Barry makes the pipeline appear less as a stable entity 'about' which information can be searched and passed on, and more as an entity that is bound up with that information. Since a pipeline is very different from a juridical-political notion such as the 'health claim', my analytical approach is to question the relation between materiality and information rather than treat it as a given; that is, I am interested in the extent to which the materiality of food - its composition, texture, chemical properties, etc. - comes into play in constituting the health claim as an informational category. Food, or the 'aliment as that which nourishes the body' (Sanabria and Yates-Doerr, 2015), is a relational object by definition; it is called 'food' because it gets eaten. Food's materiality relates, by definition, to the human body. Health claims would seem to reinforce that relation, although this material relation is brought into question when health claims are transformed into 'information'.

More broadly, I am concerned with how something is made into an object of government. The production of information is one particular way to transform a thing into a governable object. For example, Frohlich (2017) characterizes the nutrition label in the US context as 'information infrastructure', thereby emphasizing that the provision of information on food labels is more than a knowledge-fix; that is, it restructures markets and the possibilities of food technology. Similarly, STS scholars have also paid increasing attention to the conceptual and material consequences of EU legislation, for example in terms of the performativity of legal texts (Faulkner, 2012) and 'bureaucratic nominalism' (Lezaun, 2006).

In Lezaun's (2006) research on GMO regulation and traceability, bureaucratic nominalism means attributing fixed names to biological events. Coupled to 
specific detection methods, this nominalism creates an 'infrastructure of referentiality'; the regulation gives the biological event an unambiguous nominal and material referent. As I show, the creation of 'health claims' and their differentiation into specific types of claims scientifically validated by the EFSA have, arguably, set up an 'infrastructure of referentiality'. However, this infrastructure does not result from the creation of unambiguous categories. The regulatory process and its implementation that I analyze show that the making of a new informational category is only possible through what I call referential displacement, which is a political process that shifts the relation between information and its referents and, thereby, changing the type of information that is being produced.

As a result, the regulation of health claims shows how this new market can be conceptualized as a technological zone (Barry, 2006) that displaces the boundary between food and drugs. Barry introduces this concept as a way to understand how common standards and criteria of qualification are produced across the EU Member States in order to enable the circulation of objects within a space that is defined by those standards and criteria (the zone). At various moments in the regulatory process that I analyze, referential displacement enables the production of a new kind of information for food: information that implies a similar efficacy as pharmaceutical drugs, without interfering with the actual pharmaceutical market (or zone).

\section{Research Methods}

The research for this paper is based on qualitative research that I carried out between 2010 and 2014 (Hendrickx, 2013, 2014, 2017). I gathered empirical material from three main sources: written documents; interviews; and participant observation. Written documentation included legislative texts; white papers and Parliamentary reports; scientific articles from journals in the field of nutrition, law and pharmaceutical science; websites; business newsletters; and advertisements.

In parallel, I undertook participant observation at 15 scientific colloquia and professional seminars organized by a) the European Authorities, such as EFSA's Stakeholder Consultative Platform; b) industry groups, such as symposia on scientific evidence for health claims organized by the International Life Science Institute and Health Claims Europe; c) lawyers and consultancy groups, such as the European Food and Feed Law Seminars; and d) other organizers to discuss health claims for broader publics, such as the Royal Dutch Academy of Sciences. These colloquia were participative during lunch breaks, conference dinners and informal talks outside the conference setting. On two occasions, I was a keynote speaker at a conference for nutritionists.

Finally, I discussed text analyses and field observations in 24 in-depth interviews with various actors, including: EFSA panelists; EC officials; scientists; and 
industry representatives and consultants. The textual sources, interview material and field notes have been given equal attention in the analyses.

\section{Information in EU Food Law and the Austria Case}

In EU food law and policy, information has increasingly become a political device to enable the circulation of foodstuffs within the EU's Single Market. Foodstuffs are complex and densely entangled with cultural-traditional and sociotechnical regimes within the Member States. Although some recipe laws exist, controlling the composition of certain foodstuffs, it is generally easier to oblige the display of information on all foodstuffs than to control the composition of different types of food (Macmaolaín, 2007). Legislation that applies to all foodstuffs across the board is also called horizontal legislation, in contrast to the vertical legislation of the recipe laws. The EU has shifted from such vertical legislation to more and more horizontal legislation (Macmaolaín, 2007; Van der Meulen, 2009).

One of the earliest pieces of horizontal legislation was the European Directive 79/112/EEC on food labels (European Council, 1979). This Directive specifies that consumers should not be misled by information appearing on food labels. It also prohibits the making of medicinal claims on food labels; claims concerning the cure, treatment or prevention of human diseases. This poses the question of whether claims referring to health (rather than prevention of disease) are medicinal claims or not. The EU Member States sometimes have differing views of what medicine and medicinal claims are. One country that took a clear initiative with respect to health claims was Austria. Austria subjected products with such claims to a pre-market approval procedure, as some claims were considered medicinal and unlawful according to the 1979 Labeling Directive. In 2000, the EC challenged Austria before the European Court of Justice (ECJ) on the grounds that Austria was not respecting the principle of mutual recognition between Member States concerning products that circulate within the EU market.

The EC argued that Austria posed an obstacle to the free movement of goods. ${ }^{3}$ This case (henceforth, Austria) set a specific interpretation of the prohibition of medicinal claims as defined by the 1979 Labeling Directive. While Austria argued that misleading statements are a potential danger to public health, the Commission insisted that health-related statements are a form of information, thereby inscribing these statements firmly within the legal framework of the Labelling Directive.

The Advocate General followed this argument. As the Labeling Directive prohibits misleading information, the Advocate General argued during the case, no additional measures (such as Austria's premarket approval procedure) are justified to prevent misleading claims. The next question was whether or not health-related statements (as they were not yet called 'health claims') infringe 
upon the prohibition to put medicinal claims (about disease prevention) on food products. The very concept of a health claim could be misleading, and liable to prohibition, because all references to health could be classified as medicinal claims. Here, however, legal reasoning is not concerned with ontology (Latour, 2010) with the Advocate General simply stating that 'health' and 'disease' have different meanings so, logically, claims about them are different too. As such, health claims are not medicinal claims, and other forms of misleading information are prohibited anyhow.

With 'misleading information' conceptually covered and padlocked by the Labeling Directive, the Advocate General reasoned that Austria's argument about dangers to public health can, logically, only concern extremely hypothetical cases where non-misleading information about health would somehow induce the wrong assumptions or encourage dangerous behavior on the part of consumers. The Advocate considered this to be a very marginal risk which did not justify any further protective measures that would hamper free trade. Case closed.

This case illustrates the extent to which the Labeling Directive - a political instrument facilitating trade through information - was mobilized as a powerful juridical resource with the effect of turning questions about public health into free trade issues concerning information. As information, the veracity of a health claim becomes juridically unrelated to the efficacy of the foodstuff, potential side-effects and consumer interpretation. The foodstuff is out of the juridical picture, and consequently the differences or similarities between food and drugs become a matter of statements.

In sum, Austria shows how health claims became framed as a problem concerning the EU Internal Market. Anticipating other cases brought to the Court, it only took a couple of months before the Commission issued a legislative proposal to regulate health claims once and for all at the EU level. Below, I show how this proposal reshuffles the meaning and scope of 'information' with respect to what that information refers to.

\section{Drafting the Regulation (2003-2006): Nutrient Profiles and Risk Reduction}

Only months after the ECJ ruling, the meaning of 'information' and its relation to materiality started mutating, as the 'health-related statements' of the court case were transformed through regulation into health claims as a pan-European object of government (Lezaun, 2006). This change is represented by 'Proposal 424 , ${ }^{4}$ which was a legislative proposal for a European-wide regulation for nutrition and health claims (European Commission, 2003). It initiated a lengthy codecision procedure between the European Parliament and the Council of Ministers. ${ }^{5}$ In this section, I discuss two key issues where the concept of information changes, along with what the information refers to, in this regulatory proposal. The first issue concerns nutrient profiles and the question of which foodstuffs 
can carry health claims in the first place. The second is the concept of 'risk reduction', which enables indirect references to disease prevention and stretches the strict separation of health and disease defended in the ECJ ruling.

\section{Nutrient Profiles}

Proposal 424 states the following objectives for making a Regulation:

... to achieve a high level of consumer protection by providing further voluntary information, beyond mandatory information foreseen by EU legislation; to improve the free movement of goods within the internal market; to increase legal security for economic operators; to ensure fair competition in the area of foods; to promote and to protect innovation in the area of foods. (European Commission, 2003, p. 3)

The relation between information and the functioning of the internal market is clearly the main framework that underpins the legislative proposal. As complementary and voluntary information, it would seem as though a health claim is treated as an 'extra piece' of information about a given and known property of the food product. The statement and the object seem perfectly separable; either an extra statement is attached to the object, or it is not. If a product contains vitamin C, for example, then something can be said about the benefits of vitamin $\mathrm{C}$ to human health (provided that the claim is scientifically substantiated, see below).

Even if the benefits of vitamin $C$ are well-established, the proposal is not about food supplements (covered by a separate legislation) that consist of only vitamin $\mathrm{C}$ or a combination with other vitamins and minerals. The future Regulation must cover food as such, including chemically complex industrial foods. The category of 'food' includes, for example, soda drinks and breakfast cereals, where the benefits of vitamin $\mathrm{C}$ would need to be measured with respect to other criteria such as sugar content.

Giving voluntary information in the context of health claims is not simply about adding extra bits of available information; instead, it involves choices concerning the approach that is going to generate extra information. In other words, for health claims to become possible as a form of information, another type of information must be generated that concerns the so-called 'nutrient profile' of the product that carries the claim. Making a statement about vitamin $\mathrm{C}$, then, is dependent on criteria that determine which foods are eligible to carry health claims in the first place:

Some consumer organizations in the European Union consider that products that do not have a 'desireable' nutritional profile, such as candies, high salt and high fat snacks, or high fat and sugar biscuits and cakes should not be allowed to bear claims. (European Commission, 2003, p. 4)

The use of inverted commas for the word 'desireable', indicates that the establishment of nutrient profiles was not expected to be possible through objective criteria. In Proposal 424, the Commission was not in favor of nutrient profiling: 
Although based on understandable concerns and important arguments [...] the concept of prohibiting the use of claims on certain foods on the basis of their 'nutritional profile' is contrary to the basic principle in nutrition that there are no 'good' and 'bad' foods but rather 'good' and 'bad' diets. (European Commission, 2003, p. 4)

The rationale for a regulation that allows health claims on individual foods if foods are to be considered as neither 'good' nor 'bad' is unclear. To understand some of this, it must be kept in mind that Proposal 424 was addressed to the Council and the Parliament, since the Commission has to try and strike a balance between the interests of its various stakeholders. For industry heavily represented through various kinds of special committees within the Parliament - evaluating foodstuffs on the basis of nutritional profiles was to be avoided, as it might privilege or disadvantage some sectors over others (e.g. dairy versus snacks and drinks). Industry also feared that such profiles would open the door to other uses, including; 'traffic light labeling' (a simplified but visible indication of a product's profile in terms of health); restriction on the contents of advertisements; or the taxation of certain products (ERNA, 2011). ${ }^{6}$

However, as the Commission noted, certain Member States and consumer organizations expressed concern about health claims appearing on foods that are rich in sugar, fat or salt. Therefore, the establishment of nutrient profiles was proposed on the basis of contents in fat, saturated fatty acids, trans-fatty acids, sugars, and salt/sodium. The Commission added that such profiles:

... shall be based on scientific knowledge about diet, and nutrition, and their relationship to health and, in particular, on the role of nutrients and other substances with a nutritional or physiological effect on chronic diseases. (European Commission, 2003, p. 17)

Although the Commission claimed early on that nutrient profiles - portrayed as judgments about 'good and bad foods' - is scientifically questionable, it subsequently pointed to the need for scientific knowledge to determine for which products health claims can become a meaningful source of information. The point was not well-taken. Here is an excerpt of the opinion of the Committee on Industry, Research and Energy in the first reading of the proposal:

Your draftswoman takes a very critical view of the Commission proposal, and considers that many aspects require changes. [T] he Commission's intention is that the sugar, salt or fat content, in particular, of foods will have to be measured before they may be advertised with nutrition or health claims. However, the classification of foods into those with a beneficial nutritional profile and those with a less beneficial profile contradicts the idea of a balanced diet. There are, in principle, no good or bad foods. The decisive factor, instead, is the proportions in which foods are consumed. Moreover, the draft regulation largely leaves open the precise definition, and establishment, of the concept of a nutritional profile. Until this is resolved scientifically, nutritional profiles should not be introduced. (European Parliament, 2005, p. 40, my emphasis) 
Again, it can be argued here that, if diet is what really counts over and above nutrient profiles, health claims on individual foods make little sense. The call to wait for a scientific solution is a call for postponement, as there are several ways to approach this question scientifically, rather than one. Establishing a nutrient profiling scheme implies a series of decisions to make the production of information possible (Verhagen and van den Berg, 2008), which raises issues with whether profiling must be done 'across the board' (i.e. one scheme for all foodstuffs) or per food category (e.g. cereals, cheese, biscuits, soda drinks, ...). It also problematizes the criteria on which food categories can be established (e.g. fat content, sugar content, sodium, etc.). For example, what reference amounts should be used for these contents? Is a scoring system preferable over a threshold system? Is emphasis put on qualifying or rather on disqualifying ingredients, or both?

Each of these decisions has commercial and political consequences, making the establishment of a pan-European nutrient profiling scheme problematic. Cheese-exporting countries, for example, fear that the fat content of cheese may put traditional products in a bad daylight. ${ }^{7}$ For reasons already indicated, industry was largely wary of nutrient profiling. Some organizations resisted, while others tried to take advantage of a first-mover position to design the rules of the game. Industry think-tank ILSI Europe proposed a nutrient profiling scheme (Tetens et al., 2007), and so did the food giant Nestlé (Nestlé, 2009). The European Consumer Organisation (BEUC) was in favor of a nutrient profiling scheme to be established by the Authorities. Yet, in April 2016, 10 years after the first draft of the NHCR, the Parliament voted in majority against the introduction of such profiles, because they could become misleading; that is, it would allow food producers to claim nutritional value, even if there is none. 8

Nutrient profiles illustrate the extent to which the political and legal constitution of the health claim is premised on an interplay between transparency and concealment (cf. Barry, 2013). While the claim emphasizes information about the healthy properties of a food constituent, information about the foodstuff or aliment retreats into the background. Furthermore, the discussion about nutrient profiles illustrates that this is not a question of showing only part of the picture, while another part remains in the shadow. That would presuppose that there is an entire coherent picture to be seen. Rather, the discussion shows that one piece of information can only exist at the expense of another piece of information. In the context of health claims, nutrient profiles provoke the fear that one piece of information might invalidate another piece of information (i.e. the health claim itself) or, on the contrary, give the opportunity to some to make a product look healthier than it is. Information's constitutive outside is paradoxical in this case, in that food-related health claims are only possible as long as food itself remains out of the picture. 


\section{Risk Reduction Claims}

In light of the Austria court case, all references to (preventing, treating, curing) human disease are prohibited when making health claims. The Commission commented on this in its legislative proposal:

[I]t has to be considered whether this total prohibition is still adapted to the advances of research, science and food technology, as well as to consumers' expectations. This proposal for a Regulation on the use of claims maintains the prohibition on claims referring to the prevention, treatment or cure of a human disease, however a difference between 'prevention' and 'reduction of a disease risk factor' is made and a derogation is provided. Indeed, it is acknowledged that diet and certain foods can make important contributions to the support and maintenance of health, and that diet and certain foods can play a role in the management of certain disease risk factors. (European Commission, 2003, p. 7, my emphasis)

Referring to the advances in research and food technology, the Commission argued that it must be made possible for companies to refer indirectly to disease. While the European Court of Justice remained within the register of the 1979 Labeling Directive where statements are a form of information, the Commission mobilized the register of food and technology's materiality to argue that claims can be broadened to address disease risk factors. Therefore, a different type of claim and a new kind of information became possible.

The Commission's legislative proposal basically advances two types of claims, which were taken up in the final Regulation three years later (in 2006) without any significant traces of discussion in the Parliament or the Council; these are 'general function' claims (Article 13.1) and 'risk reduction' claims (Article 14). ${ }^{9}$ These concepts had already been proposed by an industry think tank called the International Life Sciences Institute (ILSI) and further developed by them (see Diplock et al., 1999; Aggett et al., 2005; Aggett, 2009). The Commission made reference to ILSI's reports in its Proposal 424. I have analyzed these concepts and ILSI's claims to science in detail elsewhere (Hendrickx, 2017).

Function claims refer to:

... the role of a nutrient in growth, development and the functions of the body; or psychological and behavioral functions; or [...] slimming or weight-control or a reduction in the sense of hunger or an increase in the sense of satiety or to the reduction of the available energy from the diet. (European Council, 2006, p. 17)

Examples are: 'Biotin contributes to normal functioning of the nervous system'; 'Beta-glucans contribute to the maintenance of normal blood cholesterol levels'; 'Calcium contributes to normal muscle function'. ${ }^{10}$ The function claim makes no reference to disease, but to the support of, contribution to, or maintenance of 'normal' bodily functions (which are supposed to jeopardize health when not functioning normally).

Risk reduction claims are different. The idea of reducing a risk factor brings the concept of disease in close relation to a health claim, albeit through an 
intermediate step; namely, reducing a risk factor - one of several possible risk factors - does not necessarily entail that one is treating, curing or preventing disease onset. This shows again that the crafting of a regulation for health claims as a form of voluntary information depends itself on a framework that enables the generation of new types of information - a constitutive outside. In this case, risk reduction claims depend on the concept of the 'disease risk factor' and the possibility of its reduction. This made it possible for a product like cholesterol-lowering margarine to remain on the EU market and in the local supermarket.

These two types of claims show that the health claim gives a particular meaning to health and its relation to disease, premised on the concept of risk; for function claims, it is the risk that a normal body function might not function properly if not supported. For risk reduction claims, it is the control of a risk factor that is believed to contribute, though indirectly, to the onset of disease. To make the health claim possible, bodily capacity or function has to be conceptualized as in a deficient state, or as in a suboptimal state. The operationalization of this health concept was further reinforced through the establishment of an evidence-base for claims by the European Food Safety Authority (EFSA), as I discuss in the next section.

\section{Implementing the Regulation: The Role of Science and Clinical Trials}

After a series of food scandals in the late 1990s and early 2000s (e.g. BSE, dioxin), independent science became an ever more important political tool to maintain the Single Market and to restore consumer trust in that market (Lezaun and Groenleer, 2006; Levidow and Carr, 2007). The generation of information, on the one hand, and the centralization of scientific authority within the EFSA, on the other, are important elements in the historical reform of EU law and policy central to understanding how health claims became an object of government and regulation (Lezaun, 2006).

The Nutrition and Health Claims regulation (NHCR) stipulates in Article 13 that health claims must be based on 'generally accepted scientific data' and 'well understood by the average consumer'. There is a lot to say about the figure of the 'average consumer', its legal definition, and other versions of the consumer that co-exist in food legislation, but I cannot discuss that point in any detail here. ${ }^{11}$ It is, however, important to keep in mind that the protection of the Market and of the consumer form one and the same project; the creation of an informational landscape in which consumers make 'informed choices'. ${ }^{12}$ In a related domain, Lezaun and Schneider (2012) note the distinct political and regulatory dynamics of functional foods and foods derived from genetically modified organisms, and the failure of EU regulatory agencies to assign a definitive meaning to these forms of artificiality. The open-endedness of these regimes, they argue, delegates part of the responsibility for evaluating food products to 
consumers as choice-making agents. The health claim regulatory regime is also open-ended in that new claims can be submitted to EFSA if they comply to the Authority's scientific guidelines.

The decision to appoint EFSA as a gatekeeper between health claims and the market is a political one, combining the protection of the Single Market and that of the consumer through one central point of control (i.e. EFSA) and through one political and market device (i.e. information). ${ }^{13}$ Protecting the market and protecting the consumer form one and the same project, reflecting the creation of a coherent zone of qualification (Barry, 2006) with the right conditions for consumers to make choices, as the NHCR says, 'in full knowledge of the facts' (European Council, 2006, referral 8, p. 2). EFSA, then, became the verifying instance for those facts relating to whether the food or food constituent is really capable of what it claims. The political requirement to provide 'accurate', 'honest', 'truthful', 'scientifically-based' and 'reliable' information to consumers thereby points to the material food ingredient and the human body. ${ }^{14}$

The non-introduction of nutrient profiles kept the foodstuff or 'aliment' at bay in favor of separate ingredients. The risk reduction concept was designed to create a distinction with pharmaceuticals, while strategically allowing an indirect and conceptual reference to prevention and the pathological. The sense in which health claims became 'information' in relation to food, health and the body, was based on the parameters set out by the NHCR - parameters that had themselves shifted since the ECJ court case and the co-decision procedure. The space between statements and their material referents was configured in a specific manner.

It would now be reconfigured again. Even though the NHCR stipulated that a pre-market scientific assessment procedure by EFSA would be established, it was by no means clear which scientific criteria were going to be used. Industry think tanks and lobby groups such as ILSI Europe had prepared the way for an 'evidence-based nutrition science' based on risk factors, biomarkers, and a meta-science of aggregated data through statistical correlations (Aggett, 2009; Biesalski et al., 2011). Evidence-based nutrition was geared to avoid all reference to the clinical, and indeed the human body itself (Hendrickx, 2017).

Keeping away from the 'clinical body' meant avoiding confusion with drugs and its regime of pre-market approval based on costly and labor-intensive clinical trials. When EFSA made clear that it wanted clinical evidence (EFSA, 2011a, 2017), the clinical body made an unexpected, and for many unwelcome, return. This decision set new terms for the production of health claims as information, and it risked drawing in the register of materiality through human bodies responding to actual food products in clinical trials.

Food products, as a main referent, had already been displaced in favor of separate nutrients. Nutrient profiles put the health claim at risk as a meaningful type 
of information, as we have seen. Now that the EFSA pushed the concept of 'health' into the realm of clinical evidence, it was 'health' that put the health claim at risk of becoming absurd. Clinical trials are geared to make visible the efficacy of a treatment for a given pathological condition. If a nutrient is demonstrated to treat a pathological condition, it is no longer a nutrient but a drug. Therefore, the only way to design clinical trials for food-related health claims is to work with a healthy population in a trial and demonstrate that they become healthier. How you discriminate between healthy and healthier is the issue I discuss below with reference to function claims and risk reduction claims.

\section{Function Claims}

Putting into practice the procedures of the NHCR, all available evidence for existing function claims was gathered by the EFSA and evaluated between 2007 and 2012. Thousands of claims submitted to the EFSA were reduced and regrouped into 4,637 claims. Between roughly 2007 and 2011, opinions on groups of related claims were periodically released in 'batches'. By 2012, a Community List of 222 approved claims was published on the basis of these evaluations (Commission Regulation, 2012). ${ }^{15}$

This Community List is valid for the EU, and food companies can use these claims if the conditions of use are respected, such as the amounts of the beneficial nutrient that the overall product must contain and the number of servings of the product necessary for the claimed effect (e.g. one yoghurt drink a day, or three slices of bread with vegetable spread). This information must also be added to the food label. If the food company respects these conditions, then it need not go through an individual evaluation procedure, as the Article 13.1 function claims are considered 'generic'. The large majority of approved claims concern vitamins and minerals, the characterization and properties of which have been well-established over some time.

Article 13.5 claims are also function claims but not part of this generic list. They are new function claims where the applicant must deliver a portfolio of the claim with scientific evidence. It is not necessarily complicated to back up one's claim with data.

EFSA approved a claim, for example, about sugar beet fiber for which the applicant (Nordic Sugar A/S) had done an Internet search on the MEDLINE database and Google for relevant existing studies (EFSA, 2011b). The applicant had found 4 human intervention studies (of which two were randomized) and three animal studies. Two randomized studies showed the claimed effect, and the animal studies were considered to provide additional supportive information. EFSA approved the claim, formulated as follows: 'sugar beet fibre increases faecal bulk', for a target population of 'people who want to improve or maintain a normal bowel function', and for foods 'high in fibre' as defined in Annex to the NHCR of 2006 (EFSA, 2011b, p. 2). 


\section{Risk Reduction Claims}

Claims concerning the reduction of a disease risk factor, pose a particular problem. First there is the question of which bodily state counts as a disease. For example, specific probiotic studies on the prevention of traveler's diarrhoea have been rejected by the EFSA for a variety of reasons, including insufficient statistical description and high drop-out rates of trial subjects (EFSA, 2009). An interesting reason for EFSA's opinion, with respect to the distinction between health and disease, is that preventing diarrhoea is not in itself accepted as a clinical endpoint. The EFSA considers diarrhoea as a disease, implying that a risk reduction factor must be identified and validated if the claim is to be approved. Scientists and companies working on probiotic applications have contested this decision, but to no avail so far. ${ }^{16}$

On the other hand, for products like cholesterol-lowering spreads, the category of the risk factor has proven an opportunity to market a product which has no direct causal relation to cardio-vascular diseases. So, the risk reduction factor cuts two ways: It has been lucrative for margarine spreads. But until now it has proven problematic for probiotics, where studies exist on symptom relief but where 'risk factors' are difficult to define.

After initial controversies and debates (Hendrickx, 2013, 2014), a picture of EFSA's evaluations and working methods came to be better understood by industry applicants in the past few years, thanks to EFSA guidance documents and stakeholder meetings. The solutions proposed operationalize the health benefit by defining specific trial populations. In that sense, the health claim and candidate products are redefining health and human bodies for their own purposes.

One solution is to extrapolate trial results from a diseased population to a healthy population, which is, depending on the case and methods used, acceptable to EFSA (EFSA, 2011a). Next, specialized research and development labs and think tank ILSI Europe have designed another solution to perform RCTs, by using what I call borderline populations. These are people that are in a 'suboptimal' state of health (e.g. Gallagher et al., 2011). For example, a study group with a body mass index (BMI) between 25 and $35 \mathrm{~kg} / \mathrm{m}^{3}$ constitutes a borderline population between BMI categories of overweight (25.0-29.9) and obese (30.039.9). They are neither normal nor pathological - or a bit of both. It is a population 'at risk'. Within such a group, ingredients, claimed to regulate a person's appetite, can then be tested for weight management products.

Similar setups can be designed to test a molecule's agency on a population with suboptimal cholesterol levels, and to relate this agency to the reduction of risk factors for cardiovascular diseases. This grey area provides a territory for testing food ingredients' performances in terms of risk reduction. It enables the making of claims that go further than simply maintaining health through generic, functional claims, while avoiding interference with the 
testing ground of pharmaceuticals. Clinical trial expert Joerg Gruenwald, a much-invited keynote at health claims conferences, and president of the private lab Analyse \& Realize says that:

You need at least one good clinical trial, randomized placebo controlled, which is in the population that is accepted by EFSA. It doesn't have to be totally healthy, but it has to be accepted, and there are all these borderline cases where they say: ok this is still a reflection of the general population. ${ }^{17}$

Industry scientists search for ways to comply with EFSA by working on classification margins, as the citation above indicates. The informational requirements that have to be met for putting health claims on products inform and requalify the division between food and drugs, health and disease, and the human bodies that participate in clinical trials. These clinical trials are designed to reflect the robustness of the drug trial and evidence-based medicine, while operating in a territory that is differentiated from drug production. The issue of trial populations shows that the normal and the pathological become displaced as referents for health claims in order to become 'information'. Slightly repositioning the border with pharmaceuticals and their market is what drives health claims in the EU.

\section{Referential Displacement}

How, in the end, did the NHCR define a health claim? Article 2 of Chapter 1 defines a health claim as: 'any claim that states, suggests or implies that a relationship exists between a food category, a food or one of its constituents and health' (European Council, 2006). Reading only this definition, it is difficult to imagine the ways in which specific types of claims have been operationalized, such as risk reduction claims (defined elsewhere in the Regulation), nor the politically sensitive difference between a food (or food category) and a food constituent. This general definition collapses a series of crucial displacements that configure a limited number of possible relations between the health claim and its referents.

In line with Barry's (2013) research on the construction of a pipeline, the chronology of the NHCR and its implementation show that information does not necessarily come as an additional piece of disclosure on a road to towards more transparency. It is not the case that the real properties of food are now available as information after a centralized scientific check by EFSA. To make health claims possible, a series of decisions needed to be made concerning the referents of the health claim.

As a result, current health claims are no longer the 'health related statement' that the Austria court case referenced. This difference as it unfolded over time is what I call referential displacement. Every step in the regulatory process towards the stabilization of the health claim as a form of information was accompanied 
by a step sideways, thus displacing a referent of that very information: from food and its nutritional profile to separate food constituents; from health to disease risk factors; and from healthy bodies in a trial population to borderline subjects.

Food's materiality is problematic and its relation to information remains ambiguous. Even though products display their composition on the food label, the health claim suggests a relation between food composition and health that has not been turned into information. Health claims apply to separate nutrients only, even if they appear on food products. Food's materiality, meanwhile, is sidelined in politics, despite being emphasized in the marketplace. Even though EFSA challenged health claims by imposing clinical evidence and bringing in the materiality of living bodies in trials, referential displacement meant that new terms were set to manage the materiality of bodies in trial setups. Similar to the issues with nutrient profiles, referential displacement has kept materiality at bay.

This is not surprising, in view of the initial problem that health claims posed, their resemblance to medicinal statements and drugs. The material referents of the health claim - food products as matrices of nutrients in relation to the clinical health status of human bodies - risk challenging the status of health claims as mere 'information' and the boundary between specific foods and drugs.

\section{Conclusion}

In this paper, I have examined how health claims became objects of government (Lezaun, 2006), and how they were placed within the juridical framework and provisions concerning labeling and information. The turn to more horizontal legislation in EU food law and increased emphasis on the role of information for the well-functioning of the Single Market does not in itself explain why, and especially how, health-related statements on food products have been turned into information and which consequences this has produced.

I have argued that it is important to attend to what Barry (2013) calls information's constitutive outside'. This outside hinges on techno-political discussion, lobbying and decisions where the boundary between health and disease is at stake, along with food's materiality. I have shown that the outside is not a stable backdrop against which information's value and veracity can be assessed, but that it is bound up with the production of information. The concept of referential displacement that this paper develops shows how decisions in the regulatory process have transformed controversial references to health on food labels into health claims as an informational category, primarily by shifting the relation between the health claim and its referents. There is a political space between the health claim and its material referents: the production of information was possible only through a particular configuration between words and things. 
Information is not a straightforward concept and it has never been defined in itself in the Nutrition and Health Claims Regulation (NHCR). With referential displacement, the visual metaphors of transparency and concealment become problematic in capturing how and which information is made public. The metaphor suggests that there is a whole and coherent picture to be seen, if only all information were public. Yet, as this paper shows, information was not produced with the same tools and referents at different key moments of the legislative process and its implementation. Producing information about food ingredients came at the expense of other frameworks to generate information, such as nutrient profiles. Similarly, trial populations defined as being 'in suboptimal health' are a way to market claims for risk reduction by displacing both health and the body as referents.

This displacement sets a new framework from which to generate information at the expense of approaches based on clear symptom relief which would draw health claims into the realm of pharmaceuticals. At various moments in the regulatory process, referential displacement enables the production of a new kind of information that suggests the efficacy of drugs, without interfering with the zone or market of pharmaceuticals. As a result, in regulating and implementing health claims, information has the specific role to create a 'technological zone', in Barry's (2006) terms, while redrawing the boundary between food and drugs in the EU market.

\section{Notes}

1. Personal Interview, Brussels, 23 April 2013.

2. The award was an initiative from the Dutch branch of Foodwatch, which is also active in France and Germany. A discussion can be found (in Dutch) here: https://www. foodwatch.org/onaangepaste-producten/becel-pro-activ/

3. C-221/2000 Commission vs Austria ECR I-1007.

4. This is my shorthand to refer to the document. For the full reference, see: European Commission (2003).

5. Such a proposal initiates the so-called 'normal procedure' (previously called codecision procedure) where the EU Parliament and the Council of Ministers read the proposal and comment on it.

6. ERNA is the European Responsible Nutrition Alliance, an international federation of food and food supplement industries.

7. Personal interview, Brussels, 17 February 2012.

8. Source: https://www.thedailymeal.com/travel/european-parliament-votes-get-ridnutrient-profiles-food-products/041516.

9. The NHCR makes further subdivisions, which we have simplified here. Article 13 also contains 'new function claims' (Art.13.5) based on original research and with the possibility of a limited protection of proprietary data. Article 14 is divided into risk reduction claims - Art. 14 (1) (a) - and claims referring to children's development - Art. 14 (1) (b). We do not treat the latter claims here seperately, as they concern a vulnerable group rather than a different type of claim. 
10. Drawn from the online EU Register of nutrition and health claims: http://ec.europa.eu/ food/safety/labelling_nutrition/claims/register/public/?event=register.home

11. See Lezaun and Schneider (2012) for the relation between governance and the figure of the consumer in the cases of GMOs and functional foods. See Meisterernst (2013) for an overview of the changing figure of the consumer in European Food Law.

12. In 2011, the Labeling Directive and the NHCR were integrated into a general Regulation 'on the provision of food information to consumers' (European Council, 2011).

13. This throws another light on the Austria case, discussed above. A pre-market approval procedure is not necessarily an obstacle to free trade, as the EFSA evaluates claims to ensure continued free trade. It is not the pre-market approval in itself that is at stake, but the political level governing that approval.

14. My collection of adjectives used by the Commission in its legislative proposal 424 on page 8 .

15. It has been amended two times since, to include additional authorized claims, which leads to a total number of 229 authorized function claims since October 2016 (last verification by author on 16 October 2018).

16. A petition, signed by 192 scientists, was published on the now defunct website www. gut-health.eu

17. Transcribed from a podcasted interview by NutraIngredients reporter Shane Starling: http://www.nutraingredients.com/Regulation/Clinical-trial-design-in-the-new-EUhealth-claims-regime-Now-we-have-to-work-on-the-borderline

\section{Acknowledgements}

This article has benefitted from the insightful comments of two anonymous reviewers and the editors of Science as Culture. I would like to thank Ine Van Hoyweghen for comments on earlier drafts of this article. I also thank Vinciane Despret for drawing my attention to the awkward definition of health as a 'deficient state' in health claims. Errors and omissions remain my responsibility alone.

\section{Disclosure statement}

No potential conflict of interest was reported by the author.

\section{Funding}

The initial research for my doctoral dissertation was funded by the University of Liège under grant number NF-09/17. The research and writing for this article were supported by a postdoctoral mandate of the Research Foundation - Flanders (FWO), grant number 12S5817N.

\section{Notes on contributor}

Kim Hendrickx is Postdoctoral Research Fellow at the Flemish Research Foundation (FWO), and at KU Leuven within the Life Science \& Society Lab of the Centre for Sociological Research (CeSO). He studies science, technology, and governance in relation to the human body; epigenetics; food and botanicals. He works across anthropology, philosophy and the life sciences and has published in Configurations, Frontiers in Genetics, and Health. 


\section{ORCID}

Kim Hendrickx (D) http://orcid.org/0000-0003-1238-8922

\section{References}

Aggett, P. (2009) The process for the assessment of scientific support for claims on food, European Journal of Nutrition, 48(Suppl. 1), pp. S23-S26.

Aggett, P., Antoine, J.-M., Asp, N.-G., Bellisle, F., Contor, L., Cummings, J., Howlett, J., Müller, D., Person, C., Pijls, L., Rechkemmer, G., Tuijtelaars, S. and Verhagen, H. (2005) PASSCLAIM - Process for the assessment of scientific support for claims on foods. Consensus on criteria, European Journal of Nutrition, 44(Suppl. 1), pp. S1-S30.

Barry, A. (2006) Technological zones, European Journal of Social Theory, 9(2), pp. 239-253. Barry, A. (2013) Material Politics: Disputes along the Pipeline (Oxford: Wiley-Blackwell). Biesalski, H. K., Aggett, P. J., Anton, R., Bernstein, P. S., Blumberg, J., Heaney, R. P., Henry, J., Nolan, J. M., Richardson, D. P., van Ommen, B., Witkamp, R. F., Rijkers, G. T. and Zöllner, I. (2011) 26th Hohenheim consensus conference. Scientific substantiation of health claims: Evidence-based nutrition, Nutrition, 27, pp. S1-S20.

Commission Regulation (EU) (2012) No 432/2012 of 16 May 2012 establishing a list of permitted health claims made on foods, other than those referring to the reduction of disease risk and to children's development and health. Text with EEA relevance. OJ, L 136:1-40.

Davis, T. and Schneider, T. (2008) Making sense of health foods: A historical analysis of food advertising in The Australian Women's Weekly in the three post-war decades, in: M. Koc, R. MacRae and K. Bronson (Eds) Interdisciplinary Perspectives in Food Studies, pp. 47-59 (Whitby: McGraw-Hill Ryerson).

Diplock, A. T., Charleux, J.-L., Crozier-Willi, G., Kok, F. J., Rice-Evans, C., Roberfroid, M., Stahl, W. and Viña-Ribes, J. (1999) Scientific concepts of functional foods in Europe -consensus document, British Journal of Nutrition, 81(S1), pp. S1-S27.

Directive (1979) Council Directive 79/112/EEC of 18 December 1978 on the approximation of the laws of the Member States relating to the labeling, presentation and advertising of foodstuffs for sale to the ultimate consumer. Official Journal of the European Commission, L 33/1.

EFSA (2009) Scientific opinion on the substantiation of a health claim related to Bimuno ${ }^{\mathrm{TM}}$ and reduction of the bad bacteria that can cause traveller's diarrhoea, EFSA Journal, 1105, pp. 1-9.

EFSA (2011a) General guidance for stakeholders on the evaluation of Article 13.1, 13.5 and 14 health claims, EFSA Journal, 9(4), 2135, pp. 1-24.

EFSA (2011b) Scientific opinion on the substantiation of a health claim related to sugar beet fibre and increasing faecal bulk pursuant to Article 13(5) of Regulation (EC) No 1924/ 2006, EFSA Journal, 9(12), 2468, pp. 1-8.

EFSA (2017) Scientific and technical guidance for the preparation and presentation of a health claim application (Revision 2), EFSA Journal, 15(1), e04680, pp. 1-31.

ERNA (2011) Nutrition and Health Claims in the EU. A Review of the Consequences of Implementation (Brussels: ERNA [European Responsible Nutrition Alliance]).

European Commission (2003) Proposal for regulation of the European Parliament and of the Council on nutrition and health claims made on foods. Brussels: European Commission. $\operatorname{COM}(2003) 424$ final.

European Council (EC) (1979) Directive 79/112/EEC of 18 December 1978 on the approximation of the laws of the Member States relating to the labelling, presentation and advertising of foodstuffs for sale to the ultimate consumer. OJ L33/1. 
European Council (EC) (2006) Regulation No. 1924/2006 of the European Parliament and of the Council of 20 December 2006 on nutrition and health claims made on foods, OJ, L 404, 30 December: $9-25$.

European Council (EC) (2011) Regulation No 1169/2011 of the European Parliament and of the Council on the provision of food information to consumers. OJ, L 304, 25 October.

European Parliament (2005) Report on the proposal for a regulation of the European Parliament and of the Council on nutrition and health claims made on foods. Brussels: Committee on the Environment, Public Health and Food Safety. A6-0128/2005 Final.

Faulkner, A. (2012) 'Law's performativities: Shaping the emergence of regenerative medicine through European Union legislation, Social Studies of Science, 42(5), pp. 753-774.

Frohlich, X. (2011) Imaginer des consommateurs, constituer les sujets: l'étiquetage nutritionnel aux Etats-Unis, 1945-1995, Science de la Société, 80, pp. 11-27.

Frohlich, X. (2017) The informational turn in food politics: The US FDA's nutrition label as information infrastructure, Social Studies of Science, 47(2), pp. 145-171.

Gallagher, A. M., Meijer, G. W., Richardson, D. P., Rondeau, V., Skarp, M., Stasse-Wolthuis, M., Tweedie, G. C. and Witkamp, R. (2011) A standardized approach towards PROving the efficacy of foods and food constituents for health CLAIMs (PROCLAIM): Providing guidance, British Journal of Nutrition, 106(Suppl. 2), pp. S16-S28.

Hendrickx, K. (2013) Rivalling evidence-bases and politics in regulatory science, Food Science \& Law, 4, pp. 125-128.

Hendrickx, K. (2014) Bodies of evidence: An anthropology of the health claim. Doctoral dissertation, Université de Liège, 2014.

Hendrickx, K. (2017) Working imagination along the food-drug divide, in Verschraegen G., Vandermoere F., Braeckmans L., Segaert B. (Eds), Imagined Futures in Science, Technology and Society, pp. 65-87 (London and New York: Routledge).

Jauho, M. and Niva, M. (2013) Lay understandings of functional foods as hybrids of food and medicine, Food, Culture and Society: An International Journal of Multidisciplinary Research, 16(1), pp. 43-63.

Latour, B. (2010) The Making of Law. An Ethnography of the Conseil d'Etat (Cambridge and Malden: Polity Press).

Lehenkari, J. (2003) On the borderline of food and drug: Constructing credibility and Markets for a functional food product, Science as Culture 12(4), pp. 499-525.

Levidow, L. and Carr, S. (2007) Europeanising advisory expertise: The role of 'independent, objective and transparent' scientific advice in agri-biotech regulation, Environment and Planning C: Government and Policy, 25(6), pp. 880-895.

Lezaun, J. (2006) Creating a new object of government: Making genetically modified organisms traceable, Social Studies of Science, 36(4), pp. 499-531.

Lezaun, J. and Groenleer, M. (2006) Food control emergencies and the territorialization of the European Union, Journal of European Integration, 28(5), pp. 437-455.

Lezaun, J. and Schneider, T. (2012) Endless qualifications, restless consumption: The governance of novel foods in Europe, Science as Culture, 21(3), pp. 365-391.

Macmaolaín, C. (2007) EU Food Law. Protecting Consumers and Health in a Common Market (Portland: Hart Publishing).

Mariotti, F., Kalonji, E., Huneau, J. F. and Margaritis, I. (2010) Potential pitfalls of health claims from a public health nutrition perspective, Nutrition Reviews, 68(10), pp. 624-638.

Meisterernst, A. (2013) A new benchmark for misleading advertising, European Food and Feed Law Review, 2, pp. 91-96.

Nestlé, M. (2007) Food Politics. How the Food Industry Influences Nutrition and Health (Berkeley: University of California Press).

Nestlé, S. A. (2009) The Nestlé Nutrient Profiling System (Vevey: Nestec Ltd). 
Penders, B. and Nelis, A. (2011) Credibility engineering in the food industry: Linking science, regulation, and marketing in a corporate context, Science in Context 24(4), pp. 487-515.

Sanabria, E. and Yates-Doerr, E. (2015) Alimentary uncertainties: From contested evidence to policy, Biosocieties, 10(2), pp. 117-124.

Schleifer, D. (2013) Categories count: Trans fat labeling as a technique of corporate governance, Social Studies of Science, 43(1), pp. 54-77.

Scrinis, G. (2008) Functional foods or functionally marketed foods? A critique of, and alternatives to, the category of 'functional foods', Public Health Nutrition 11(5), pp. 541-545.

Scrinis, G. (2013) Nutritionism. The Science and Politics of Dietary Advice (New York: Columbia University Press).

Tetens, I., Oberdörfer, R., Madsen, C., de Vries, J. (2007) Nutritional characterisation of foods: Science-based approach to nutrient profiling. Summary report of an ILSI Europe workshop held in April 2006. European Journal of Nutrition, 46(Suppl. 2), 4-14.

Van der Meulen, B. (2009) The system of food law in the European Union, Deakin Law Review, 14(2), pp. 305-339.

Verhagen, H. and van den Berg, H. (2008) A simple visual model to compare existing nutrient profiling schemes, Food \& Nutrition Research, 52. doi:10.3402/fnr.v52i0.1649

Weiner, K. (2010) Configuring users of cholesterol lowering foods: A review of biomedical discourse, Social Science \& Medicine, 71, pp. 1541-1547.

Weiner, K. and Will, C. (2015) Materiality matters: Blurred boundaries and the domestication of functional foods, BioSocieties, 10(2), pp. 194-212.

Williams, P. (2005) Consumer understanding and use of health claims for foods. Nutrition Reviews, 63(7), pp. 256-264. 